\title{
LOS PASOS APRESURADOS, DE DACIA MARAINI
}

\author{
THE HURRIED STEPS OF DACIA MARAINI
}

Juan Carlos DE MIGUEL

Universitat de València

Juan.C.Miguel@uv.es

Resumen: Passi affrettati (Pasos apresurados) es una obra nacida en el año 2005 de la mano de Dacia Maraini, su autora, una mujer experimentada y relevante en el campo de las letras y del teatro italiano. De duración corta-media se propone clara y directamente como un teatro de intervención social sobre el maltrato y la violencia contra las mujeres. Parte de la narración-representación de ocho historias «ejemplares» verídicas, procedentes de diversas partes del mundo, protagonizadas por mujeres. Prevé un formato de lectura dramatizada de fácil transporte y siempre un debate final con el público asistente. Su alta eficacia queda probada por las numerosas representaciones exitosas habidas, normalmente en circuitos parateatrales, en toda Italia y también en otros países. Un teatro de combate, pues, propuesto desde la persuasión y el diálogo. Aquí se analizan las estrategias y los mecanismos (de escritura, de puesta en escena, de la entera función) precisos como un reloj, que están en la base de esta pieza dramática aparentemente sencilla pero en realidad muy elaborada. 
Abstract: Passi affrettati (Hurried Steps) was written in 2005 by Dacia Maraini, an experienced playwright with an outstanding profile in the world of Italian literature and theatre. The medium-length play, which develops the theme of mistreatment of women and domestic violence, belongs very clearly to the theatre of social commitment. It takes the form of a dramatized narration structured around eight true «exemplary» stories drawn from several parts of the world, all which have women as their protagonists. This format is conceived as one which allows it to be taken easily taken from place to place, and it always ends with a discussion with the audience. Its effectiveness has been demonstrated by the numerous successful performances there have been, normally in the para-theatrical circuits, in many parts of Italy and also in other countries. It is a theatre of social struggle, a vehicle of persuasion and dialogue. The present study analyzes the strategies and mechanisms (the written text, the mise en scène, the theatrical event as a whole), all as precise as clockwork, that underlie this outwardly simply but actually highly elaborate piece of theatre.

Palabras clave: Teatro italiano. Siglo XXI. Violencia de género. Dacia Maraini.

Key Words: Italian theatre. XXI century. Gender violence. Dacia Maraini.

\section{LA DRAMATURGA}

Dacia Maraini, nacida en Fiésole en 1936, es una de las voces vivas más relevantes y conocidas en el actual panorama de las letras italianas. La escritura es en ella una vocación bien temprana, incluida la escritura dramática. Su primer texto, La vacanza, de índole narrativa, se publica en 1962, pero bien pronto aporta su primera pieza teatral, La famiglia normale, que ve la luz en la revista Sipario, en 1966 y que se estrenará al año siguiente. En seguida vendrán Il ricatto a teatro (1967) y otras comedias, un conjunto que comparte el ser un teatro pobre y su insistencia en los motivos metateatrales. De 1969 es Il manifesto, una denuncia sobre las prisiones femeninas. Por entonces Dacia Maraini va tomando conciencia de que en el teatro italiano faltan papeles femeninos relevantes, carencia que ella intenta suplir con su producción, que prevé dar la palabra largamente negada a las mujeres. Así nacerán, entre otras muchas, obras como Dialogo di una prostituta con un suo cliente (1973).

Los años setenta del siglo XX fueron para Dacia Maraini un laboratorio en el que el teatro de calle se junta con experiencias en pequeños locales, con 
el feminismo militante más efervescente y con el compromiso con gentes y barrios marginales romanos, como el de Centocelle y la Magliana. En este ambiente ella aprende todos los oficios teatrales, incluido el de directora escénica; sólo quedará fuera de su experiencia el de actriz. Son los años en los que con frecuencia la acompañan Pier Paolo Pasolini, Alberto Moravia y un amplio grupo de artistas, escritores y gente del mundo de la cultura. Eran tiempos en los que la dimensión colectiva era prevalente en muchas iniciativas teatrales y artísticas. De hecho, tras su experiencia primeriza, de finales de los sesenta, del teatro de la calle Belsiana con la Compañía del Puercoespín, llegaría el del Teatro della Maddalena, vinculado a un colectivo femenino y feminista.

Y mientras tanto, y en las décadas siguientes, va creciendo la incansable Dacia narradora, novelista, poetisa, ensayista, crítica, periodista, columnista, allegada de varias maneras al cine, etc. Ha hecho incursiones de relectura en los clásicos griegos (I sogni di Clitennestra, 1978), ha hurgado en biografías de grandes personajes femeninos (Suor Juana, 1979; I digiuni di Catarina da Siena, 1999), ha insistido en dar voz a los excluidos, no ha renunciado a la palabra de autora, primero escrita, después recitada y más tarde impresa, aunque ella misma, como decíamos, haya dirigido muchos montajes. Es una autora que ama contar historias. Su teatro está lleno de contenidos y de matices. En el año 2000 la editorial Rizzoli editó Fare teatro, una recopilación en dos volúmenes de unos cuarenta textos, los más importantes de una autora que años después ha seguido creando y estrenando. Y así hasta nuestros días. Es fundadora y directora desde su inauguración, en el año 2000, del Festival Teatro di Gioia, que en 2010 alcanza ya su décima edición. Se viene celebrando en Gioia dei Marsi, un pueblecito del Abruzzo, con un cartel de primera línea. Allí mismo Dacia Maraini, al calor del festival, creó una Escuela de dramaturgia.

Su recepción en España ha sido irregular, llena de altibajos. Se la ha traducido pero no lo bastante, o no siempre se la ha difundido suficientemente. Maria Estuarda (1980), un gran éxito internacional suyo, fue estrenada en España por Magui Mira y Mercedes Sampietro. En los últimos tiempos la editorial Herce, de Madrid, parecía haberla retomado como autora señalada de su catálogo, pero tras la edición de Voces y de La larga vida de Marianna Ucría, textos narrativos, ambos en 2008 , se ha entrado en una fase de silencio ${ }^{1}$.

${ }^{1}$ Sobre la obra de Dacia Maraini, véase Cattaruzza (2000), Cruciata (2003) y Diaconescu-Blumenfeld y Testaferri (2000). 


\section{EL TEXTO}

Passi affrettati es una pieza de teatro breve compuesta por ocho historias de mujeres, que se suceden una tras otra.

La primera es la de Lhakpa, una tibetana que salió de su aldea a los catorce años para enrolarse en el ejército chino y fue violada por cinco soldados.

La segunda es la de Aisha, joven jordana ${ }^{2}$ que vive encerrada en su pequeño poblado y se dedica, junto con su hermana, al pastoreo del rebaño familiar, bajo la mirada autoritaria, castradora, de su cruel padre. Maltratar diariamente a las mujeres, gritarles, pegarles, es algo cotidiano, normal, en el poblado. El hermano, sin embargo, por ser hombre, es considerado benevolentemente y adorado por toda la familia. La madre ha parido diecinueve veces, pero, como el resto de sus congéneres, a la mayoría de las hijas las ha ahogado al poco de nacer, sólo el hijo varón ha salvado el orgullo del padre. Un día aparece Ahmed, un hermoso muchacho del poblado, Aisha se enamora enseguida, quisiera casarse con él; en su compañía se siente persona. Pero la situación no es fácil: el joven, no obstante, se ofrece a hablar con el padre. Por otra parte, pronto muestra ser un chico celoso. Al cabo de varias semanas se unirán físicamente, ella accede por temor a perderlo; Ahmed le hará promesas, de amor, de no abandonarla nunca, pero no negociará con el padre. Al poco Aisha se queda embarazada. Cuando su madre lo descubre se desencadenará el furor y la venganza de la familia. A la mañana siguiente, sus padres se van a la ciudad y su cuñado queda encargado de quemarla viva. Lo hace rociándola de gasolina.

La protagonista de la tercera historia es Carmelina, una joven italiana, de la Puglia. Su padre, un albañil, murió al caer de un andamio, y no hay manera de que el seguro indemnice a su familia. Rosario, el hermano de Carmelina, ha contraído deudas con su compadre Cosimo. Éste le presiona, le amenaza, pero Rosario no dispone del dinero. Es entonces cuando el chantajista repara en la hermosura de Carmelina, que ya es una adolescente, de trece años, bien guapa, y virgen. Al final, Rosario colaborará en el estupro de su propia hermana a cambio del condono de la mayor parte de la deuda.

La cuarta historia consiste en el recuerdo por parte de una hija de la violación que sufrió su madre por obra de las tropas aliadas, en Ciociaria, cerca de Roma, las mismas que iban a liberar al país del yugo nazi.

\footnotetext{
${ }^{2}$ Esta condición se afirma en el Prefacio del libro, no propiamente en el texto teatral.
} 
La quinta consiste en un diálogo mantenido con un comisario por parte de una mujer maltratada y de su marido, en un lugar de Bélgica. Pese a los daños sufridos, ella prefiere perdonarlo. Le reconcilian con su cónyuge sus horas de dulzura y ternura, cuando no bebe. Siente pena por él. Por otra parte, se viene a saber que el marido, a su vez, de niño fue maltratado por su padre.

La sexta historia alcanzó difusión internacional. Es la de Amina, la nigeriana condenada a ser lapidada por haber tenido un hijo sin casarse. La ley religiosa era inflexible y se imponía a la civil del país. La criatura recién nacida se habría quedado sin madre y desdeñada para siempre en su entorno.

La séptima historia tiene por protagonista a un matrimonio mexicano emigrado a California. Él se siente frustrado, menoscabado frente a la libertad y la autonomía de su mujer. Acabará asesinándola mediante un disparo de pistola.

La octava y última historia es la de Viollca, una niña albanesa, que es llevada a Italia por una red de trata de blancas con el consentimiento de sus padres. A algunos clientes les gustan las niñas vírgenes. Cuando Viollca es forzada se siente casi muerta. El caso de Viollca ya había aparecido en un libro anterior de Dacia Maraini (1999). Estamos, pues, ante un caso de intertextualidad de autor ${ }^{3}$.

Todas estas historias, según ha declarado su autora, proceden de informes de Amnistía Internacional, entidad que de hecho es patrocinadora de la obra, y podían encontrase en las páginas de sucesos de los periódicos.

\section{EL ESPECTÁCULO}

Passi affrettati nació en el año 2005 a raíz de un encargo efectuado por la Asociación Archivio Disarmo, de Roma, a su autora. Esta asociación es un instituto parauniversitario de investigación, fundado en 1982, que estudia los problemas del control de las armas, de la paz y de la seguridad internacional. El 7 de marzo de 2005 la entidad celebró un congreso sobre Guerra e violenza sulle donne. Testimonianze e proposte a confronto, en el Liceo Classi-

\footnotetext{
${ }^{3}$ «Viollca la bambina albanese» es un relato inserto en Buio (Maraini, 1999), un libro narrativo que recoge, entre otras, diversas historias de jóvenes y niños excluidos. La versión de Passi affrettati parte indudablemente de este relato. Se reproducen muchos fragmentos literalmente y se recorta mucho la trama. El elenco de personajes permanece prácticamente inalterado. En la primera versión hay más crueldad y más explotación, sin embargo el desenlace es más esperanzado. Y se transcriben más frases en albanés, sin duda para aumentar el efecto de realidad.
} 
co T. Mamiani, de Roma. La pieza se representó como clausura de la jornada. Se anunció como azione scenica y con el título completo de Passi affrettati. Guerre, violenze contro le donne ${ }^{4}$. Fue interpretada por los actores Barbara Amodio, Miriam Bardini, Monica Guazzino, Giuseppe Moretti e Vincenzo Preziosa, bajo la dirección artística de Carlina Torta en la plaza del Capitolio, sede del Ayuntamiento de Roma ${ }^{5}$. El texto se editó como libro por vez primera en marzo del 2007. La autora ha renunciado a los beneficios que le corresponden, tanto del libro como de la recaudación de los espectáculos, en favor de una asociación italiana que se ocupa de mujeres maltratadas.

Con independencia de los detalles de la vicisitud concreta del encargo, de lo que no hay duda es de que se le solicitó a la autora por su idoneidad para el mismo, pues Dacia Maraini, según hemos visto, aúna tanto la faceta de ser una experimentada dramaturga y perfecta conocedora de todos los oficios teatrales, como su acreditado prestigio en el terreno de la lucha en favor de las mujeres, de la que era, y es, una campeona.

A partir, pues, de esta primera representación, debió de saltar la chispa y encenderse la llama de la difusión de la pieza, que alcanzaría incluso una dimensión internacional y sigue viva hasta hoy. Actualmente hay una pequeña productora (Agens) que gestiona la difusión y un portal web, propagador e impulsor de la iniciativa, en el que puede consultarse, entre otros muchos datos, el itinerario representativo que ha ido desarrollando la obra (http://www.passiaffrettati.it).

Dicho portal se presenta en versión italiana, francesa, inglesa y japonesa e incluye traducciones de la pieza a dichas lenguas ${ }^{6}$. La difusión empieza con lentitud, discurre poco a poco, y en 2008 ya despega el vuelo, con 22 representaciones, incluida una primera puesta en escena foránea, en París, el 20 de noviembre en la Université Paris 13 en el campus Villetaneuse. Esto implicó

\footnotetext{
${ }^{4}$ El segundo título, o subtítulo, como se ve, incorpora el leitmotiv de la reunión congresual, pero lo reformula ligerísimamente. Al editarse en libro se cambió el subtítulo: «Testimonianze di donne ancora prigioniere della discriminazione storica e familiare».

${ }^{5}$ Observo alguna discrepancia sobre este último dato. En la nutrida página de memoria de congresos de Archivio Disarmo (http://www.archiviodisarmo.it/template.php?pag=55438) se lee que la actividad se realizó en el mismo instituto público de enseñanza Mamiani, en el que tuvo lugar el congreso, pero interrogada la propia Dacia Maraini, no dudó en contestar que la sede fue el Capitolio: «Mi dispiace, ma non ho il tempo adesso di controllare. Comunque sono sicura che non si tratta del liceo Mamiani. La prima volta abbiamo rappresentato Passi nella piazza del Campidoglio, ma l'anno non me lo ricordo» (Comunicación privada al autor de esta ponencia, de fecha 21/II/2010).

${ }^{6}$ Señalamos, por su interés, las siguientes ediciones: Maraini (2007) y Maraini (2009a y b). Todas mis citas, y los números de página, son de la edición italiana. Las traducciones son mías.
} 
la primera traducción de la obra a otra lengua. Después de Francia vendrían Gran Bretaña, España y Suiza.

El estreno español nos cupo el orgullo de realizarlo en Valencia, en la Universitat de València, durante los días 23 y 24 de abril del año pasado (2009), en el marco de un Congreso internacional de estudio de la obra y de homenaje a la autora ${ }^{7}$. Entonces una reducida compañía local completó su cuadro artístico, inicialmente formado sólo por tres actores y pudo poner en pie la performance ${ }^{8}$. Como quiera que Dacia Maraini asistió al Congreso, ella misma quiso y pudo dar los últimos retoques de dirección escénica, tendentes a conjuntar y a eliminar los excesos verbales o gestuales que excediesen una línea de austeridad.

Estas representaciones de la obra en el exterior se han hecho siguiendo dos criterios fundamentales, queridos por la autora, que marcan las líneas maestras de la relación con el público: por una parte se ha de dar a los espectadores el mensaje en su propia lengua y, por otra, muy relevante, se ha de buscar una compañía de actores locales que encarnen a los distintos personajes. Es decir, un acercamiento máximo a los espectadores, para que sientan como suyo el espectáculo y el conflicto que plantea.

En Valencia la obra se ofreció un día en español y al día siguiente en valenciano y la compañía — como queda dicho- era efectivamente de arraigo local.

Casi tan importante como la propia puesta en escena es el coloquio con el público que sigue a la misma. En él suele estar presente Dacia Maraini, a menudo acompañada de expertos del lugar en los conflictos de género. El debate se ve facilitado por el tipo de locales en los que se actúa y por el tipo de espectadores que asisten. En términos generales Passi affrettati se exhibe en circuitos alternativos, ajenos a los grandes teatros comerciales, esto es, circuitos escolares, de enseñanzas medias y universitarias, en teatros municipales y a veces en aulas y en salas de reuniones. Extraordinariamente se ha dado al aire libre o en otros espacios. La iniciativa de buscar y reclamar el espectáculo la suelen tomar los grupos locales interesados, asociaciones, colectivos, ONGs, luchadores por la paridad, concejalías de igualdad, etc. El diálogo con el público siempre cuaja, más allá de que pueda costar más o

${ }^{7}$ Dacia Maraini: scrittura, scena, memoria, femminismo (cf. http:www.uv.es/migueljc/maraini). Las actas de la reunión, con sus contenidos reformulados, pueden consultarse en de Miguel (2010).

${ }^{8}$ El grupo CRIT (Companyia de Recerca i Innovació Teatral) está formado por los actores Josep Daniel Tormo, Anna Marí y Josep Vicent Valero. Y para la ocasión de Passi affrettati se unieron Rosanna Pastor, Maribel Bravo, Pau Esteve y Pau Pons. 
menos empezarlo, y muy a menudo no hay más remedio que suspenderlo, a causa de su excesiva duración, no por falta de intervenciones.

Personalmente he asistido a varios de estos coloquios — que sin duda, pueden tener matices diferenciados-, pero siempre he apreciado la insistencia de Dacia Maraini en dos ideas madre: por una parte, la universalidad del conflicto, del maltrato de las mujeres, de su postergación, que no distingue razas, religiones, continentes, clases sociales, etc. Por otra parte, su naturaleza primordial de conflicto político, esto es, de poder; el factor sexual, de búsqueda del placer, por ejemplo, es irrelevante frente a un problema de dominio del hombre sobre la mujer, de sometimiento y humillación.

Lo que se busca, pues, es concienciar, calar en las mentes de los presentes. Incluso los escolares siguen en completo silencio la puesta en escena y quedan impactados por lo que se les transmite. He conocido algún caso, aislado, de personas que han encontrado demasiado violento el contenido, tal vez les parecía que había una recreación en el dolor, o que se lo banalizaba, no lo han podido resistir y se han ausentado de la representación.

He hablado de representación, pero quizás el término se puede prestar a malentendidos y requiere una explicación sobre las coordenadas escénicas básicas de esta obra. La producción estándar de Passi affrettati requiere unas prestaciones humildes. Sobre un escenario desnudo y oscuro unas luces iluminan cinco atriles; al poco de comenzar a sonar una música en la que predominan apremiantes tambores, salen a la escena, en fila india, a paso rítmico, tres actrices y dos actores vestidos de negro, para confundirse con el ambiente. Cada uno de ellos porta en la mano su libretto, lo apoya sobre su atril, y comienza lo que en propiedad debe ser llamado la lectura dramatizada.

La eficacia teatral, pues, queda confiada a la voz, a la palabra y al gesto facial y corporal; no hay desplazamientos, no hay movimientos importantes sobre el escenario, sí cruce de miradas, complicidades explícitas y también desencuentros. Una banda sonora marca breves pausas entre cada una de las historias, a modo de cesura. Pero sobre estos mimbres mínimos, la fuerza del texto y de su lectura permite atrapar al espectador.

La performance de Passi affrettati dura una hora escasa, sin pausa intermedia. Creo que este lapso consiente incluirla dentro de lo que puede denominarse teatro breve. O tal vez, en nuestro ámbito artístico, sea una duración de frontera: un poco larga para un teatro breve, un poco breve para un teatro extenso o estándar. 


\section{EL ANÁLISIS DE LA ESCRITURA DRAMÁTICA}

La esencialidad que caracteriza a esta obra hace más necesario, si cabe, un estudio detenido de su escritura dramática, intentando escrutar los mecanismos subyacentes que en ella operan. Ya ha quedado expuesto que Dacia Maraini siempre ha cuidado sus textos teatrales y en esta ocasión no podía ser menos.

En primer término, se ha de destacar la decisión, estratégica pero arriesgada, de no desarrollar una única trama, lo que obviamente le habría permitido una mayor complejidad de los personajes y del argumento, sino optar por una sucesión de historias o microsecuencias, necesariamente sucintas, concentradas, aunque no todas en la misma medida. Las ocho historias aumentan la polifonía, introducen variedad y sirven al propósito de mostrar la universalidad del conflicto, que afecta tanto al llamado primer mundo como al segundo y al tercero.

Un evento sucede en el Tibet, otro en un poblado indeterminado de Jordania, otro en Puglia - Italia-, otro en un pueblo cercano a Roma, otro en Bélgica, otro en Nigeria, otro en California (pero la familia protagonista ha emigrado desde México) y el último a caballo entre Albania e Italia. Una cierta preponderancia italiana se explica probablemente por razones de acercamiento al primer público destinatario de la obra.

Hay diferencias internas entre las ocho secuencias, pero hay rasgos que, indudablemente, son comunes a todas, algunos son argumentales, otros más técnicos. En todos los casos se refiere una violencia grave provocada por uno o más hombres. La mayoría de las protagonistas son mujeres violadas y además casi siempre golpeadas, pero Aisha, por ejemplo, fue quemada por su cuñado, a Julietta su marido le abrió la cabeza y le rompió dos dientes, Amina fue condenada a ser lapidada y Teresa fue asesinada por un disparo de su cónyuge. La mayoría son mujeres jóvenes, incluso simples muchachas: Viollca es una niña de corta edad; Juliette, en cambio, parece que es una adulta y Teresa ya es madre de dos hijos.

El arranque de cada secuencia es directísimo, sin preámbulos; cada protagonista se presenta de inmediato a sí misma o, alternativamente, lo hace una Voz subsidiaria. La fórmula empleada es bien simple: «Mi nombre es Lhakpa Chungdak», «Me llamo Aisha», «Me llamo Civita», «Mi nombre es Juliette», o «María Teresa Macías, del condado de Sonora, en California...», etc. Obviamente, los destinatarios inmediatos de estas presentaciones no 
son los otros personajes sino los propios espectadores, a los que se apela, reclamando su atención, desde el principio9.

Las historias están completamente centradas en la agresión sufrida. No cabe una contextualización que no se atenga o vaya dirigida al hecho principal que se quiere denunciar: los personajes, pues, son pocos, y apenas pueden tener profundidad o evolución. Más bien son emblemas. Las dramatis personae de cada historia raramente van más allá de los agresores y las víctimas. Las pinceladas de escritura sobre los agresores tienden al retrato mínimo, a identificarlos con prototipos: soldados prepotentes y avasalladores; el padre padrone maltratador de las hijas; el joven hampón y chulesco que consiente el abuso sobre su hermana para salvarse él; el marido que cuando se emborracha se vuelve violento y agrede; el conyuge frustrado que no puede soportar una cierta independencia y autonomía de su esposa y los padres pobres e inmorales que prostituyen a su hija.

En un caso el agresor denunciado no se hace corresponder con personaje alguno: es el extremismo religioso. Es una muestra extrema del grado de abstracción de los personajes que, en alguna medida, está latente también en los agresores citados: se trata del caso de Amina [Lawal], que saltó a la opinión pública occidental en el año 2002. Es la única historia que sabemos fehacientemente — más allá del texto- que acabó bien, pues con la ayuda de la presión internacional se consiguió levantar la condena a muerte dictada por la Sharia islámica. Este episodio refuerza en el público, porque ya lo conocía, el efecto de realidad y el crédito de veracidad de toda la obra.

Las víctimas, igualmente, no se sustraen a un cierto esquematismo: hay mujeres violadas por soldados, embarazadas solteras que son rechazadas y condenadas a muerte por la comunidad local, compañeras o esposas cuyos agresores son sus compañeros o maridos y una niña y una joven explotadas sexualmente. Ahora bien, este grado de generalización tipológica se ve compensado por la manera en que Dacia Maraini conduce el relato de sus historias y el juego de interlocución que ha previsto. Además, hay tres tramas que se extienden más pormenorizadamente. Son la segunda, la tercera y la última, esto es, las que corresponden a Aisha, Carmelina y Viollca (sobre las que volveremos), mientras que las demás quedan reducidas al meollo.

\footnotetext{
${ }^{9}$ Incluso en alguna de las secuencias más extensas, como la de Viollca, los personajes no protagonistas cuando intervienen se presentan con las mismas fórmulas a la niña, pero el verdadero receptor es el público: «Yo soy Gabriella» (Maraini, 2077: 62); «Yo soy Ma’» (Maraini, 2007: 65).
} 
Como ya se ha mencionado, sobre el escenario sólo hay cinco actores, lo cual implica que todos ellos asuman diferentes papeles, diferentes personajes, a veces incluso dentro de una misma historia (caso de la segunda y de la última). El papel de la niña Viollca lo interpreta una actriz adulta. Además están las intervenciones de las Voces, de las que nos vamos a ocupar enseguida, que también se reparten entre los cinco intérpretes.

Las acotaciones son muy escasas: una de demarcación musical precede a cada una de las ocho secuencias, otras tres igualmente musicales jalonan la historia de Viollca, otra connota la voz del marido y futuro asesino de María Teresa como «frío y calmado». La secuencia más rica en acotaciones es la de Carmelina, que es sin duda una de las historias más conmovedoras. En el último episodio, el de Viollca, un narrador que interviene activamente verbaliza una escenografía, conformando una acotación implícita sui generis que configura con palabras un dormitorio de burdel: «La cama está cubierta con una piel. Hay un gran espejo ahumado. Una lamparita con perlas y una pequeña butaca tapizada de cretona a flores» (Maraini, 2007: 66).

Un punto clave es toda la problemática de la interlocución, que se sustancia en la alternancia entre la diegesi o narratio y el diálogo (o la representación propiamente dicha). No sólo escuchamos las voces de los personajes protagonistas, las víctimas, y en ocasiones también las de los verdugos, sino que, al modo de las figuras del teatro medieval y religioso, se oyen Voces que representan a instituciones de asistencia humanitaria o social, o alguna otra; así la Voz UNICEF (Maraini, 2007: 14, 15, 28, 49, 50, 53), la Voz As[ociación] Humanitaria (Maraini, 2007: 15), la Voz Women Freedom (Maraini, 2007: 45), la Voz del Poblado (Maraini, 2007: 51, 52) y la Voz Crónica (Maraini, 2007: 55). Destaca la presencia de un Narrador o Narradora y la de un Periodista en la historia de Viollca.

Las funciones de estas Voces son varias: se escuchan, graves, cual una suerte de deus ex machina y no interactúan con los personajes, sino que se dirigen directamente a los espectadores, casi como si fueran apartes, rompiendo la ficción escénica e informándolos de una serie de datos. Gracias a ellas sabemos del rígido control del gobierno chino sobre la maternidad y los embarazos de las mujeres tibetanas y de su drástica inducción al aborto (Maraini, 2007: 15). O que una de cada tres mujeres sufre alguna violencia dentro de su familia (Maraini, 2007: 48). O conocemos las estadísticas de violencia doméstica en los EEUU (Maraini, 2007: 58). O la Voz del Poblado nos informará de las bárbaras costumbres locales en Nigeria (Maraini, 2007: 51-52). Pero una Voz también es la que introduce la historia de Carmelina 
(Maraini, 2007: 31) o la de María Teresa (Maraini, 2007: 55). Y la Voz de la UNICEF es asimismo la que nos informa de cómo acabó la trágica historia de Aisha (Maraini, 2007: 28-29) o la de Teresa (Maraini, 2007: 58), etc.

Es decir, que estas Voces cumplen también funciones internas estructurales de ayudar a diseñar o completar la trama en algunas secuencias. Por otra parte, tienen una naturaleza coral, es decir, nos recuerdan al coro trágico del teatro griego antiguo, a menudo representante de fuerzas abstractas y dotado de la función de comentar e interpretar el significado moral de las acciones. Su efecto de distanciamiento de la ilusión escénica en Passi affrettati parece evidente.

Es notable la riqueza estructural y la variedad que logra crear la autora con mimbres tan delgados. El patrón que sirve de base es el drama-situación, esto es, el episodio de tenor trágico que se relata o en algún caso se desenvuelve ante nuestros ojos, pero hay excepciones y en todo caso las modalidades de articulación discursiva con que se materializa este patrón son distintas, a caballo entre el monólogo y el diálogo: la secuencia de Civita es la más corta y sencilla de todas, se resuelve en un monólogo del personaje narrador, la hija que rememora la violación de su madre por las tropas durante el avance aliado hacia el centro de Italia; la de Lhakpa consta de un diálogo evocador entre una madre y una hija y se concluye con un epílogo; la de Juliette comprende una entrevista con un comisario de policía, en la que participa su pareja, y un epílogo; la de Amina es una suerte de monólogo entre patético y poético ante su pequeña hija pero perfectamente alternado con otras dos Voces; la secuencia de Teresa también incluye al marido y a un comisario pero la estructura es algo más elaborada. No obstante, las más complejas son las de Aisha, Carmelina y Viollca, pues no en balde son también, como ya hemos citado, las más extensas. Vamos a ocuparnos de ellas sintéticamente.

La secuencia de Aisha comprende siete personajes y variados diálogos, está construida como la suma de tres segmentos y un epílogo: en el primero de ellos, según hemos visto, se da cuenta de su dura vida en familia, junto a su hermana, dedicada al pastoreo; en el segundo, se describe su enamoramiento del joven Ahmed y su posterior embarazo y en el último la condena familiar y su castigo: ser quemada viva. En el epílogo, la Voz de la UNICEF nos narra la evolución posterior del caso: sólo una médica francesa se atrevió a desafiar las leyes locales y la condujo a un hospital, pero Aisha quedó desfigurada de por vida. Es decir, que se reproduce a escala de microestructura el clásico anudarse trimembre de presentación, nudo y desenlace. Esta his- 
toria sirve para ilustrar un rasgo que comparte con la mayoría de las demás: que la violencia contra las mujeres suele proceder del propio medio familiar.

El tratamiento del tiempo es también relevante y paradigmático en esta secuencia y es una buena muestra de un uso sapiente para lograr una máxima expresividad con las restricciones que impone la brevedad. La historia en su conjunto está contenida en un lapso de cerca de un año ${ }^{10}$ y la dramaturga recurre a un eficaz artificio de ruptura de la verosimilitud de la perspectiva, alternando presente y pasado. Porque el presente, cuyo uso es mayoritario en Passi affrettati, no sólo lo emplea la protagonista que cuenta - la cual lógicamente habla desde el final de la historia y, por tanto, a veces empleará el pasado-, sino también otros personajes que han participado decisivamente en los pasos intermedios (el padre, la madre, el novio, el cuñado...) quienes se asoman con sus frases y diálogos, formulados en una suerte de presente histórico que recrea y actualiza, evocándolo, lo que en la lógica temporal ya sucedió con anterioridad. Pero de esta manera el espectador re-vive la historia, y la escucha y la ve, en boca de sus protagonistas ${ }^{11}$.

Hay que destacar, asimismo, el uso del presente para lograr la mayor eficacia expresiva y comunicativa en las hipotiposis, el viejo recurso retóricoteatral usado para exponer, sin mostrarlo, lo más terrible: se narra lo que el decoro impide representar, en esta ocasión por su alto grado de violencia:

Aisha: Me coge por el pelo y me arrastra por el suelo de la cocina. Me golpea mientras estoy arrodillada, se aferra a mi trenza como si quisiera arrancarla y en una ocasión me la corta con las tijeras grandes de esquilar. Ya no tengo pelo (Maraini, 2007: 19-20).

Estoy ardiendo como una antorcha. Grito. Escapo. El fuego me está comiendo (Maraini, 2007: 28).

El procedimiento se repetirá, por ejemplo, en la secuencia de Viollca:

$Y$ ahora el hombre se me tira encima y me ahoga apretándome la cabeza contra el pecho (Maraini, 2007: 67).

Se restriega contra mí y llora resoplando. [...] Abro los ojos y veo que el hombre se ha sacado de los pantalones una salchicha oscura.[...] Pero de repente ese hombre grotesco se pone furioso, se me tira encima, me aplasta con su cuerpo y me sacude como si quisiera triturarme (Maraini, 2007: 68).

${ }^{10}$ Cuyo transcurso está denotado por las oportunas marcas discursivas («después de una semana», «Durante un mes», etc.; Maraini, 2007: 25).

${ }^{11}$ Algo semejante, en una escala más microscópica, sucedía ya en la historia precedente de Lhakpa. 
El tiempo, decíamos, importa, pero no sólo el tiempo interno sino también el tiempo externo o histórico. Porque Passi affrettati, evidentemente, tiene vocación de actualidad. Con la excepción de la historia de Civita, que se remonta a los últimos años de la Italia fascista, ya en guerra, probablemente como homenaje a aquellas víctimas (y no por casualidad es la historia más sucinta de todas) $)^{12}$, las demás secuencias son contemporáneas nuestras, de nuestro tiempo. En algunos casos se especifica incluso el año, como en el episodio de Carmelina, que es del 2004, o en el Juliette, en el que se cita el año 2000, o en el de Teresa, cuyo asesinato data de 1996, pero en el que la Voz de una periodista menciona estadísticas del año 2001. Y en otros episodios, aunque no haya fecha exacta, los respectivos conflictos pertenecen a la contemporaneidad.

Retomando el reconocimiento de las estructuras en las historias más completas, se ha de mencionar que la de Carmelina comprende también un prólogo y un epílogo bien diferenciados, en los que - además de la protagonista - intervienen otros personajes, exclusivos de esos segmentos. El prólogo aporta una suerte de trama lateral o complementaria: el padre de Carmelina era un albañil fallecido en accidente laboral y ningún seguro se hace cargo de la responsabilidad. Éste es otro aspecto compartido con otros episodios, la denuncia de otras violencias colaterales: es el caso de los abusos de las autoridades chinas en el Tibet y su imposición del aborto a muchas mujeres (primer episodio), o el semejante asesinato de muchos neonatos, si son hembras, por parte de sus propias madres (segundo episodio), o el robo que acompaña a la violación cometida por los soldados (cuarto episodio), o el maltratador que a su vez fue maltratado de niño (quinto), o la niña que quedará huérfana si apedrean a su madre (sexto), o el marido que intenta suicidarse tras asesinar a su esposa (séptimo).

La secuencia de Carmelina se ha de destacar como aquella de toda la obra en la que el paradigma dialógico-representativo se impone por completo al diegético o narrativo, que en todas las demás secuencias o bien es dominante o al menos está presente.

La estructura del episodio de clausura, el de Viollca, es asimismo más compleja que la mayoría, reúne a 12 personajes y consta de cinco eslabones de ascendencia climática, ligados a espacios (evocados) distintos: un prólogo, brevísimo, en el país de la niña, en su casa, con sus padres; la secuencia del transporte en barco desde Albania, la acogida en una casa italiana regida

${ }^{12}$ No se puede olvidar la conexión directa de esta historia con el tema del congreso de Archivio Disarmo, en cuyo seno, como hemos explicado, nació Passi affrettati. 
por una gobernanta, el transporte en coche efectuado por dos rufianes hasta el burdel (que incluye un diálogo en el que participan exclusivamente ellos), y la estancia en la casa de citas en la que una madame facilita el delito. El personaje de la niña protagonista aparece casi en cada ocurrencia asociado a Malek, su oso de peluche. La insistencia de todos en arrebatárselo subraya un simbolismo, muy transparente, de querer arrebatarle por la fuerza su niñez y ella, a su vez, en los momentos peores, remachando el tropo, se aferra físicamente a él.

Así como en la historia de Aisha era ella misma la narradora, en este caso al tratarse de una niña la verosimilitud impone el recurso a un narrador externo, que abre la historia e interviene después. El cometido, pues, lo cumplen las mencionadas Voces: el Narrador-Narradora y, secundariamente, el/la Periodista. Estas Voces muestran a las claras el paradigma de la compresión, pues aportan, sintetizadas, informaciones de vario tipo que, expresadas en diálogos habrían alargado la acción escénica. También debe de haber repercutido en este caso el que la autora haya partido como fuente, según hemos mencionado, de otro texto suyo de naturaleza narrativa. Las repetidas intervenciones de estas Voces hacia la conclusión provocan el que los fragmentos dialogados-representados adquieran una connotación didáctica, de ilustración de un discurso principal narrado, algo semejante a lo que sucedía en la historia de Aisha.

Recapitulando: deberemos fijar nuestra atención en cómo el universo de la familia ocupa por completo la pieza, fundamentalmente porque se considera que ése es el marco de la violencia de género. Así hemos ido desgranando relaciones entre madres e hijas, padres e hijas, maridos y mujeres, novio y novia, hermano y hermana, etc. Y observaremos también que el margen para la esperanza en ese espectáculo es escaso, sólo un resquicio, pero aún así existe. Recordaremos cómo Lhakpa es consolada por su madre, o Aisha auxiliada por una médico francesa o Carmelina es socorrida por una enfermera que depondrá a su favor, o Juliette es atendida por un comisario de policía (al igual que Teresa, aunque no le evitará la muerte); y, en fin, sabemos, aunque fuera del escenario, que la historia de Amina, como ya hemos recordado, acabó bien gracias a la solidaridad internacional.

El broche de cierre absoluto del texto y del espectáculo es un hermoso poema de origen africano reformulado por Dacia Maraini; lo recita una de las actrices, en primera persona. Su título es «La adormecida». En él, mediante fórmulas de frecuente repetición, que rememoran la poesía tradicional, se canta líricamente a la resistencia de la mujer y se deja intuir un futuro despertar. 
Tal vez los pasos apresurados no sean sólo los de la mujer que intenta escapar de su agresor, sino también los que hay que dar hacia un futuro mejor.

\section{VALORACIÓN}

Ha quedado de manifiesto que Passi affrettati es una obra viajera de teatro militante. Hasta ahora los productores han optado por una puesta en escena de formato muy austero, de lectura dramática, lo cual permite un montaje sencillo y rápido en espacios distintos, que se pueden adaptar para la ocasión con muy pocos medios. Es, en consecuencia, facilísimo de transportar. Más que de teatro militante, vista la actual situación de las víctimas de la violencia de género en nuestro país, España (y en otros muchos), casi cabría hablar de un teatro de emergencia, de un equipo móvil de pronto soccorso, que acude con la voluntad de intervenir agitando conciencias, como paso educativo-preventivo del conflicto. Es, pues, también un teatro de intervención social.

Si consideramos las fuentes documentales empleadas por la dramaturga, los informes de Amnistía Internacional, según ella misma declara, bien podemos acogernos al concepto de Teatro-documento para una mejor estimación genérica de la pieza. Dicha categoría historiográfica, bastante difundida en ámbito germánico, nace ligada al teatro de Peter Weiss y al de otros autores en torno a los años sesenta del siglo XX, en el que los temas políticos e históricos se enfocan críticamente, con afán de denuncia, bajo la alargada sombra del teatro de agitación de Erwin Piscator ${ }^{13}$. En nuestros días, el teatro documento parece inescindible de los medios de comunicación de masas y de su poderosa influencia social, con Internet a la cabeza. Gracias a ellos también se difunde Passi affrettati.

Precisamente navegando en Internet he localizado este juicio de un crítico teatral:

En realidad, está utilizando la vieja técnica del teatro medieval o del teatro épico; hace un teatro popular en el sentido de que habla de las gentes - no de los poderosos - con un lenguaje de la gente; sigue el esquema brechtiano de la descripción rompiendo las escenas y yuxtaponiendo los acontecimientos que se enlazan por el narrador. Los actores y las actrices in-

${ }^{13}$ La obra Marat/Sade, de Peter Weiss, estrenada en Berlín en 1964, es una importante referencia de este género. De 1968 datan sus Catorce notas sobre el teatro documento. 
terpretan varios personajes con el mismo vestuario o casi. «La escenografía, el vestuario y la iluminación la crea el espectador», dice el narrador. [...]. Quizá, la puesta en escena no aporte nada nuevo como técnica pero posee una modernidad fabulosa. Quizá la propuesta escénica pudiera pecar de simplicidad pero, sin duda, posee una eficacia dramática contundente (Sesma, 2005: ed. el.).

Pero la sorpresa es que estos juicios no se refieren a Passi affrettati, sino a Hamelín, del dramaturgo español Juan Mayorga. Y ello nos lleva a ponderar nuestra obra italiana en un contexto más amplio y a preguntarnos si Passi affrettati es un caso aislado ligado a un país o a una lengua o a un determinado conflicto. O si, más bien, forma parte de una oleada de renovación del mundo del teatro, efectuada desde la sencillez material y el compromiso intelectual, término éste último, el compromiso, que parecía ya casi olvidado en nuestra lengua.

La respuesta nos la da Hamelín, un espectáculo de autor español actual y nos la dan otros autores italianos y otros dramaturgos y actores de otros países. Hay, pues, en marcha un cierto teatro vivo, a veces sustanciado en piezas breves, a veces más extensas, que desde la periferia del teatro más institucional busca expresar conflictos sociales fuertes de nuestro tiempo.

No puedo dejar de mencionar el llamado teatro de narración, que es una destacable novedad italiana, que surge los años noventa del siglo XX y llega a nuestros días. Passi affrettati es de una factura artística distinta, pero comparte, como decíamos, una inquietud por problemas de índole social, el dirigirse a un público que no es el habitual de los teatros y también algunas soluciones técnicas, temáticas y narrativas. Y desde luego no hay solución de continuidad porque un recientísimo libro italiano (Bernazza, 2010) trata de nuevos autores-actores-directores, como Daniele Biacchessi, Roberta Biagiarelli, Elena Guerrini, Alessandro Langiu o Ulderico Pesce, que se ejercitan en espacios alternativos que enmarcan sus encuentros de contaminación entre artes y lenguajes, teatrales o no.

\section{CONCLUSIONES}

Si bien en Italia no se vive actualmente una eclosión del teatro breve semejante a la española, hay piezas que se aproximan a algunos de sus parámetros constitutivos. Passi affrettati es un puzle teatral de historias ejemplares breves, que se presenta a la sociedad contemporánea como un aldabonazo en las conciencias, como una vulgata del maltrato de género, con relatos de 
nuestro tiempo. Un teatro político, es decir, social, pero no panfletario. En el centro de casi todas estas historias se halla la familia patriarcal, origen a menudo de perversiones y abusos, y cuyos varones, muchos de ellos, se niegan a reconocer la autonomía efectiva de las mujeres. Y junto a la familia está también la guerra, como otro foco de violencia y degradación femenina.

El tema no es nuevo, pero sí la eficacia de su tratamiento. Y en ello reside el mérito de la pieza que nos ha ocupado. La brevedad persuasiva de su duración impone el paradigma de la compresión, que se manifiesta en la inmediatez y lo directo, que todo lo dominan. A través de los mecanismos expuestos, apelando a menudo a soluciones técnicas que nos recuerdan a veces al teatro clásico griego o al medieval o religioso europeo o al épico de Brecht, se consigue el objetivo de impactar poderosamente en el público, denunciando y haciendo pensar, evidenciando sutilmente pero no mostrando la violencia. Esta insensibilizada sociedad nuestra que vive la burda exhibición de la violencia como moneda de uso corriente queda impactada en directo, sobre un escenario, por las voces que gritan el dolor y la injusticia. Y a continuación del sencillo espectáculo es llamada al debate.

Dacia Maraini, una combativa feminista en sus años de juventud, hoy, en la madurez de su vida, deja de lado lo accesorio y se centra en lo esencial: una lucha contra la discriminación, en favor de una causa universal, los derechos humanos de las mujeres, que llama a todos, miembros de la polis, hombres y mujeres, ciudadanos, sin mayores distinciones.

\section{REFERENCIAS BIBLIOGRÁFICAS}

BERNAZZA, L. (2010). Frontiere di teatro civile. Riano: Editoria \& Spettacolo.

CATTARUZZA, C. (2000). Dedica a Dacia Maraini. Trieste: Lint.

CRUCIATA, A. (2003). Dacia Maraini. Fiesole: Cadmo.

DIACONESCU-BLUMENFELD, R. \& A. TESTAFERRI (eds.) (2000). The Pleasure of Writing. Critical Essays on Dacia Maraini. West Lafayette, Indiana: Purdue University Press.

DE MIGUEL, J. C. (ed.) (2010). Scrittura civile: studi sull'opera di Dacia Maraini. Roma: Giulio Perrone Editore.

MARAINI, D. (1999) Buio. Milano: Rizzoli. 
- (2007). Passi affrettati (...). Pescara: Ianieri Editore.

— (2009a). Pasos apresurados (...). Valencia: Edicions 96.

- (2009 b). Passos lleugers (...). Valencia: Edicions 96.

SESMA, M. (2005). «Clase magistral». El Adelantado de Segovia, 18 de octubre. [También se puede leer en <http://parnaseo.uv.es/ars/autores/ mayorga/hamelin/resenyas.html>]

SUMELI WEINBERG, M. G. (1993). Invito alla lectura di Dacia Maraini. Pretoria: University of South Africa. 
